\title{
Trasformaciones en el cargo de la caja real de Santafé, 1739-1808. Un análisis cualitativo de su impacto administrativo ${ }^{1}$
}

\author{
José Joaquín Pinto Bernal \\ Universidad del Tolima, Colombia \\ jjpintob@ut.edu.co
}

Cita sugerida: Pinto Bernal, J. J. (2018). Trasformaciones en el cargo de la caja real de Santafé, 1739-1808. Un análisis cualitativo de su impacto administrativo. Anuario del Instituto de Historia Argentina, 18(2), e074. https://doi.org/10.24215/2314257Xe074

Recibido: 28 junio 2018 - Aceptado: 28 septiembre 2018 - Publicado: 07 diciembre 2018 


\title{
Trasformaciones en el cargo de la caja real de Santafé, 1739-1808. Un análisis cualitativo de su impacto administrativo ${ }^{1}$
}

\author{
Transformations in the Cargo of the Royal Treasury of Santafé, 1739-1808. A qualitative analysis of its \\ administrative impact
}

José Joaquin Pinto Bernal

Universidad del Tolima, Colombia

jjpintob@ut.edu.co

\section{RESUMEN:}

Este artículo da cuenta de los cambios cualitativos de la Real Hacienda en Santafé, desencadenados tras la aplicación de las reformas borbónicas. Los efectos de la aplicación de las nuevas medidas son estudiadas a través de la constatación del aumento del número de ramos de cargo, la aparición de nuevas oficinas de recaudo, la determinación de cambios en el recaudo y manejo de las rentas, así como en el establecimiento de nuevas instancias de control administrativo. El estudio de estos componentes aporta nuevos elementos para la comprensión de las causas del incremento de los ingresos de esta caja real, los cuales no solo estaban asociados al mejoramiento de las actividades productivas. Además de ello, se deja abierto el debate respecto a la implementación parcial del modelo de intendentes en la Nueva Granada, el cual tuvo una aplicación restringida al campo contencioso y administrativo del real erario.

Palabras Clave: Real Hacienda, Administración, Fiscalidad, Nueva Granada.

\section{Abstract:}

This paper study the qualitative changes of the royal treasurie in Santafé, unleashed after the implementation of the Bourbon reforms. The effects of the application of the new measures are studied through the verification of the increase in the number of sources of revenue, the appearance of new collection offices, the determination of changes in the collection and management of income, as well as in the establishment of new instances of administrative control. The study of these components provides new elements for understanding the causes of the increase in income of royal treasurie, which was not only associated with the improvement of productive activities. In addition, the debate regarding the partial implementation of the model of intendants in New Granada is left open, which had a partial application in the contentious and administrative field of the real treasury.

KEYWORDS: Royal Treasury, Administration, Taxation, New Granada.

\section{INTRODUCCIÓN}

El fisco neogranadino, en especial la caja real Santafé como matriz de todo el virreinato, no fue ajeno al impulso del reformismo borbónico desencadenado en la América española como producto del afán de la corona para solventar los abultados gastos de defensa que supuso la guerra entre potencias durante el siglo XVIII, materializada en varios conflictos bélicos que servirían de motor propulsor para la puesta en marcha de una serie de medidas que tendrían como uno de sus fines primordiales el incremento del recaudo de las cajas reales (Alves y Sánchez, 2012; Torres, 2018).

Estas medidas en la casi totalidad de los dominios de la monarquía católica en América generaron un significativo aumento de los ingresos fiscales, el cual ha sido interpretado por algunos como el producto de la eficiencia de la reforma y el mejor rendimiento de las actividades económicas, tal y como lo han expuesto Jauregui y Marichal (2014) para el caso de Nueva España, Gelman y Moraes para el Rio de la Plata (2014), Contreras (2014) para el Perú y Meisel (2014) para la Nueva Granada.

En efecto, las medidas de corte administrativo se caracterizaron por una mayor fuerza centralizadora como en el caso de las alcabalas (Sánchez, 2001; Ibarra, 2001) o los tributos (Marino, 2001), quitándole el poder 
a los comerciantes para su recaudo en el caso de las primeras, o a los corregidores y alcaldes en los segundos. Se trató de la creación de nuevas instancias de control y administración como las secretarias de cámara, las intendencias, así como de la estatización de rentas como el tabaco y los licores (Jáuregui, 2001). A la par de ello, algunas medidas comerciales mejoraban los niveles de intercambio con la metrópoli y al interior de cada una de las jurisdicciones, así como las políticas de fomento a través de la reducción de los gravámenes a algunas actividades productivas con el fin de combatir la evasión, provocaron la expansión de algunos sectores.

A pesar de lo anterior son pocos los trabajos que se han ocupado de los cambios cualitativos del fisco en Santafé como producto del reformismo borbónico. En tal sentido, uno de los componentes de dicho campo es la evolución de los ramos que constituyeron el cargo de la caja real de Santafé entre 1739-1808. Las investigaciones que se ocupan de dichos rubros a nivel general -comprendiendo todo el ámbito del virreinato- han avanzado de la mano de obras como las de Calderón (1911), Ots Capdequí (1946) y Rodríguez (1987). Calderón (1911), como pionero de los estudios fiscales del periodo colonial en la Nueva Granada, nos ofrece un completo recuento de distintos ramos presentes en la fiscalidad virreinal, sin lugar a dudas un rico acervo general que da cuenta de la evolución de algunas alícuotas y su manifestación particular en diferentes regiones. Ots Capdequí (1946) amplió el anterior aporte concentrándose en el estudio pormenorizado de diferentes disposiciones reales sobre el manejo de cada ramo. Por último, Rodríguez (1987) compuso en breve resumen del significado de rubro para el caso específico de Popayán.

A la par de ellos, se destacan trabajos que se ocupan de la dinámica cuantitativa de lo que llaman erróneamente ingreso ${ }^{2}$ en obras como las de Muñoz (2010), Meisel (2011) y Pinto (2015). Algo bastante llamativo y que devela la reciente conformación de un campo de estudios sobre la temática en Colombia, es que precisamente la obra de Muñoz en 2010 es la primera que toma en cuenta la diferenciación entre ramos comunes, particulares y ajenos; nacida de la reforma contable de Machado Fiesco en 1784, igualmente es Muñoz quien por primera vez publicó series de cargo y data de la caja, y a través de ellas realizó un balance del impacto de la independencia sobre la fiscalidad neogranadina. Posterior a ello, Meisel (2011) daría cuenta de los cargos de las cajas reales, aunque su trabajo no deja ver con claridad lo correspondiente a cada una en términos cuantitativos, pues los agrupa a nivel regional y temporal (quinquenios); además de ello los ramos fueron agrupados parcialmente con arreglo al método propuesto por Klein (1973). Algo similar ocurre con el trabajo de Pinto (2015) quien, a pesar de concentrarse en el estudio de la caja real, omite la exposición de los ramos y los agrupa con arreglo a los mismos criterios expuestos por Klein (1973). Ambos trabajos fueron hechos con base en los sumarios de cargo y data de la caja real.

En este contexto, el artículo aborda las siguientes preguntas: ¿Cómo el reformismo borbónico produjo cambios de corte cualitativo en la caja real de Santafé? ¿Cómo las reformas afectaron el número de ramos de recaudo, la jurisdicción de la caja real, los organismos de control, las formas de administración y recaudo? Ello a través de cuatro secciones. La primera, tiene por objeto describir la dinámica del número de ramos, la regularidad en su cobro y el mayor peso de cada uno en términos de recaudo. En la siguiente sección, a través del uso de sistemas de información geográfica, abordaremos el problema de la jurisdicción territorial bajo la cual actuaba la caja. La tercera parte está dedica al estudio de los cambios en los ramos más significativos, y por último se estudia la evolución de los organismos de control de las operaciones fiscales.

Esta exploración permitió evidenciar cómo en el caso de la caja real de Santafé se presentaron dinámicas similares a las de otras regiones del imperio, tales como la centralización, la aparición de nuevas instancias administrativas, el aumento de oficinas recaudadoras, la creación de nuevos rubros de cargo y tensiones entre los oficiales reales como producto del nuevo diseño institucional. Estos fenómenos no se dieron de una manera uniforme en términos de periodización respecto a otras colonias, ya que el impulso reformista sería más acentuado desde 1739, tras la conformación de la unidad virreinal como producto de las reacomodaciones estratégicas tras el tratado de Utrech (Eissa-Barroso, 2015) y debido a que la aceleración del proceso solo se produjo en 1778 tras el mandato del virrey Flórez y la visita de Gutiérrez de Piñeres, sufriendo 
retrocesos como producto de la rebelión de los comuneros entre 1781 y 1782 (Pinto, 2016a, McFarlane, 1997), matices que dieron un tono particular a la implementación de la reforma en la Nueva Granada.

Así las cosas, el trabajo pretende resaltar el papel del factor cualitativo asociado a los cambios administrativos como factor determinante en el incremento de los ingresos de la caja de Santafé, el cual no solo puede ser entendido como el reflejo del mejoramiento de las actividades productivas de la Nueva Granada como lo resaltan Meisel (2014) o Pinto (2018), ya que el mejoramiento de los procedimientos administrativos también fue fundamental para lograr gravar una economía más dinámica. Además de ello, el trabajo propone la exploración en futuros trabajos de instituciones que se creían inoperantes en su contexto, evaluando el impacto de los cambios en una caja real matriz de un virreinato, la cual consideramos hasta el momento poco analizada.

\section{Comportamiento de los RAMOS DE CARgo}

Una de las primeras impresiones que deja un vistazo rápido a las cuentas de Real Hacienda pertenecientes a la caja real de Santafé es el paulatino incremento de los ramos de cargo, hecho debido a la instauración de nuevas fuentes de recaudo por parte del reformismo borbónico. En términos eminentemente cuantitativos, los ramos registrados en los sumarios de cargo extractados de los libros comunes de la caja de Santafé (Pinto, 2016b) muestran que para 1739 estos se mantenían en un margen que no superaba los 40 ramos; posterior a ello en 1749 inicia un proceso de aumento sostenido hasta 1753, año en el que llegan casi a 50, tendencia que se mantiene estable hasta 1799 , salvo algunos años en los cuales la tendencia fluctúa, como se ve en la GRFICA 1.

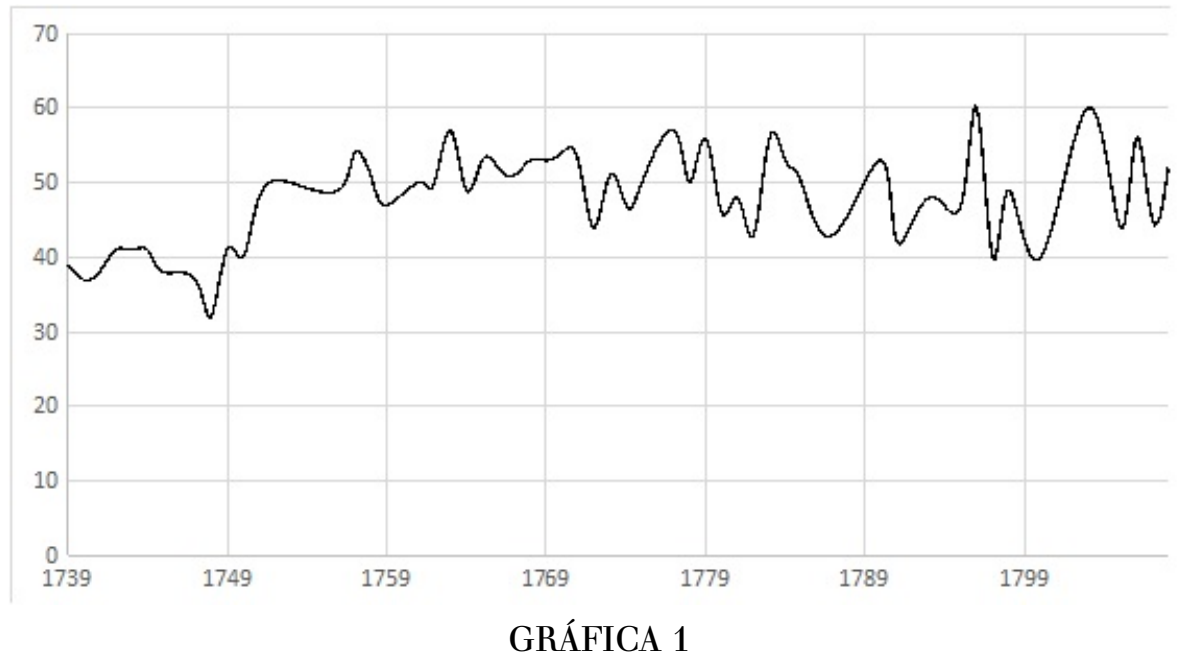

Número de ramos de cargo en la caja real de Santafé, 1739-1808

Elaboración propia con base en Pinto (2016b).

El aumento presentado para la mitad del siglo se debe a varios factores asociados a la implementación del reformismo borbónico. Por una parte la estatización de algunas rentas como el tabaco y los correos; además de ello se evidencia un mayor grado de centralización ya que cajas que antes no aparecían remitiendo fondos a la matriz empezaron a hacerlo de forma constante como Girón, Mompox, Muzo y Salazar de las Palmas. Por otra parte, se constata un mayor grado de intervención del gobierno en actividades económicas pues los azogues registraron en el cargo de manera más constante; además de ello se siguió de forma detallada el remate de efectos de bienes pertenecientes a la Real Hacienda a través del ramo de efectos beneficiados. De la misma forma se crearon nuevos rubros, como el cobro de 4 reales por cada carga de mercancías entradas a Santafé con destino a la construcción y reparación de los caminos. 
La irregularidad en el último periodo de estudio no está asociada a la desaparición de ramos, sino a la agrupación de algunos de manera poco constante, en especial las remisiones de otras cajas que, contrario a lo que aconteció en la mayor parte del tiempo donde cada remisión aparece especificada con el nombre de la jurisdicción de la cual provenía, desde 1783 en algunas ocasiones solo se consignaba bajo la denominación de otras tesorerías. A ello habría que sumar la desagregación y reunión de los novenos, así como de los tributos.

La historiografía (Phelan, 1980; Pinto, 2016b) sostiene que los ingresos de la Real Hacienda subieron considerablemente después de 1778, cuando se aplican las reformas del Virrey Flórez y el Visitador Gutiérrez de Piñeres (Pinto, 2016b), y de allí concluyen que el reformismo borbón -al menos para el caso de la Nueva Granada- tuvo su momento culmen en dicho periodo, desencadenando la rebelión comunera (Phelan, 1980). Contrario a ello, la GRÁFICA 1 deja ver que la preocupación por la imposición de nuevos rubros de recaudo estuvo presente desde por lo menos treinta años antes, versión que coindice con la propuesta de periodización de McFarlane (1997), la cual da cuenta de tres coyunturas del reformismo en la Nueva Granada: la primera entre 1717 y 1738 con la fallida creación del virreinato, la segunda entre 1738 y 1778 marcada por la instauración del virreinato y la creación de los estancos, y la última comprendida entre 1778 y 1808 caracterizada por la aplicación de la administración directa del fisco y la visita general de Gutiérrez de Piñeres. Al menos en el plano fiscal en lo que atañe a los cargos de la caja real de Santafé, el reformismo mostraría sus primeras manifestaciones a través de la estatización de rentas, la intervención en actividades productivas y el aumento de la centralización gestionando el envío de fondos de mayor número de cajas desde finales de la década del 40, y no desde finales del 70 como lo aducen Pinto (2016b) y Phelan (1980), o desde 1760 como concluye Meisel (2014).

Una vez constatado el aumento del número de ramos y su relación con el reformismo es necesario determinar la magnitud de cada uno de ellos en el recaudo. Sería erróneo establecer el monto de ingreso a través de los sumarios de cargo y data, además de sumamente engorroso si se efectúa a través de la revisión de cada una de las partidas de los libros comunes, tal y como lo muestra Sánchez (2013). Para ello, proponemos el ejercicio de calcular sus magnitudes a través del empleo de la relación de valores y pensiones de la caja para el quinquenio 1732-1737 (Tribunal Mayor de Cuentas De Santafé, 1737), además del estado de ingreso de la misma para 1784 (Caja Real de Santafé, 1784), reiterando que nuestra intención es establecer la importancia de cada ramo en su respectivo momento, así como la variación en la aparición o extinción de ramos entre las dos fechas.

En ningún momento pretendemos analizar los cambios en el recaudo, sino su peso relativo en el global de la oficina recaudadora. Cabe recordar que cada uno de los dos documentos fue elaborado con la expresa orden de registrar lo efectivamente recaudado, omitiendo débitos corrientes, atrasados, existencias y sobrantes, mismos que sí se incluyen en algunos ramos de cargo tanto en los libros comunes como en los sumarios extraídos de ellos. Así las cosas, para 1784 se registran un total de 21 ramos de cargo que son registrados y que no se encuentran en el quinquenio de los años treinta. Entre dichos rubros se encuentran los monopolios de aguardiente, naipes, salinas, pólvora y quina; junto a ellos el arrendamiento y confirmación de tierras, los derechos de camellón, la Real Orden de Carlos III, el 18\% de conducciones, los gastos de justicia, la media anata y los montepíos de inválidos, militares y ministeriales. Por otra parte se registran remisiones de cajas subalternas que antes no estaban consignadas, provenientes de Cartago, Girón, Honda, los Llanos, Mompox y Panamá. Lo que reafirma la presencia de la centralización y de la estatización de rentas.

En términos de recaudo la primera impresión infiere un crecimiento significativo, ya que para 1784 este fue de 552.578 pesos plata, mientras que para el quinquenio corrido entre 1732 y 1737 fue de tan solo de 339.532 pesos plata. Por otra parte, como lo evidencia la GRÁFICA 2, la composición de la participación porcentual de los rubros más significativos (aquellos que sumaban más del 1\%) revela un cambio de perfil del recaudo. En efecto, con anterioridad la caja mostraba una alta dependencia de rubros relacionados con la actividad eclesiástica como la venta de bulas y los diezmos, así como de las contribuciones de las comunidades indígenas. Posteriormente, se hace evidente el repunte de los estancos (aguardiente, tabaco y salinas) junto 
al aprovechamiento de los bienes de la expulsada comunidad jesuita bajo el rubro de temporalidades, aumentando también el recaudo por alcabalas. Aunque cajas como Popayán y Chocó siguieron teniendo participación, esta no es equiparable a la de la cuarta década del siglo, pues la primera pasó de aportar el 13\% total a remitir menos del 1\%, mientras que la segunda redujo su participación en casi $11 \%$.

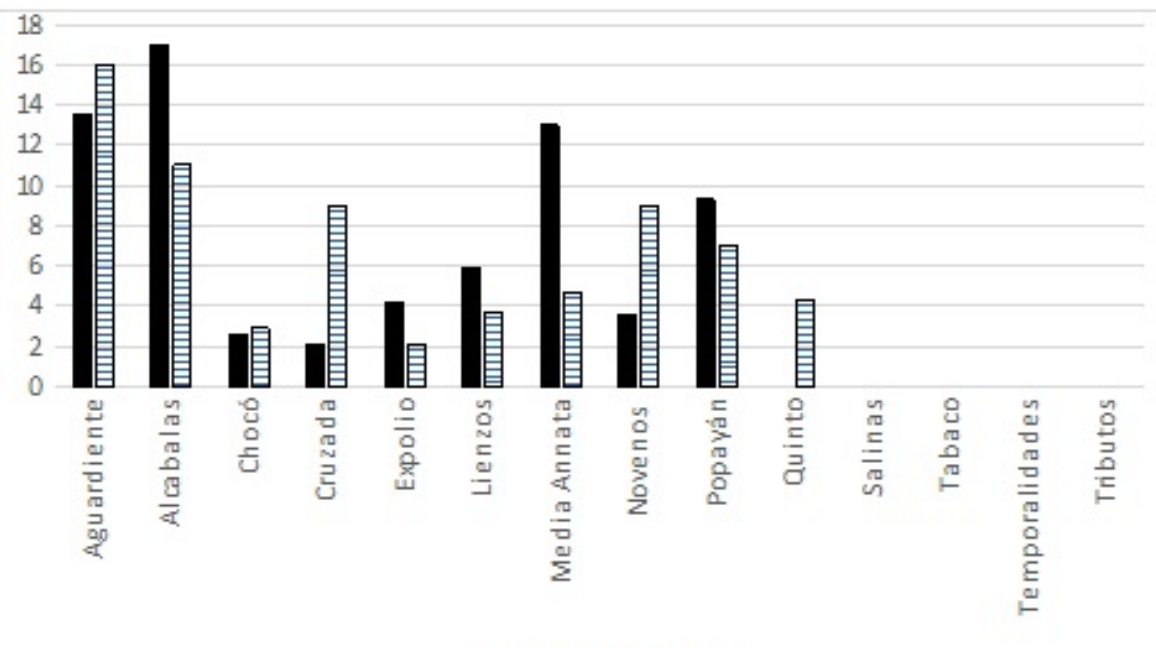

口1737-1739 日1784

\section{GRÁFICA 2}

Participación porcentual de los ramos de ingreso que aportaron más del $1 \%$ en la caja real de Santafé para el quinquenio $1732-1739$ y el año 1784 Elaboración propia con base en: Tribunal Mayor de Cuentas de Santafé, 1737 y Caja Real de Santafé, 1784.

Estos ejercicios dejan claro alguno aspectos. Por una parte es evidente que una de las características del impacto del reformismo borbónico en la fiscalidad de la caja real de Santafé fue el aumento del número de ramos que se recaudaban. La naturaleza de los nuevos deja ver que existió un proceso de centralización, ya que nuevas cajas remitieron sus fondos a la capital, además de un proceso de estatización de rentas tras la aparición de los estancos. Por otra parte, es claro que el aumento del número de los ramos como indicador de la aplicación de las reformas se dio previo a la llegada de la visita general de 1777, como lo sostienen Phelan (1980) o Pinto (2016b), 1760 como es expresado por Meisel (2014), o por lo menos desde comienzos de la década del 50, lo que concuerda con la periodización propuesta por McFarlane (1997) sobre el inicio y desarrollo de las reformas. Además de ello, la caja matriz del virreinato cambió totalmente su perfil, pues pasó de una clara dependencia de los ingresos provenientes de la iglesia y las comunidades indígenas a afianzar sus recursos en los monopolios y los gravámenes al comercio interior. Pero todo este proceso no solo impactó la naturaleza de los ramos de cargo y la participación de cada uno en el recaudo, ya que el impulso reformador debía estar acompañado de un cambio en la amplitud del radio de acción de la caja real en términos territoriales, como se verá en la siguiente sección.

\section{El TERritorio DE LA CAJA REAL DE SANTAFÉ}

Como se anunció anteriormente, el aumento del número de ramos y la necesidad de centralizar el recaudo debía estar acompañado de una ampliación de los puntos de recaudo en distintas zonas que sirvieran de remisoras de fondos para la caja real de Santafé. Para constatar tal fenómeno hemos decidido elaborar dos mapas que nos reportan las localidades desde las cuales se originaban fondos que fueron administrados por la oficina matriz, uno para el fin de la centuria y otro para el inicio. El primero de ellos es elaborado con arreglo al libro común perteneciente al tesorero Pedro Francisco de Terreros como oficial de la caja de la capital, 
correspondiente al año de 1705 (Terreros, 1705). En dicho libro se establece la procedencia de cada una de las cantidades registradas en el cargo, tanto en lo que hace referencia al pagador como a la ciudad de la cual proviene, registrando que solo cuatro ramos provienen de una jurisdicción diferente a la de la capital virreinal, a saber: los tributos, las alcabalas, los diezmos y las remisiones de algunas tesorerías subalternas.

Como se observa en el MAPA 1, la caja real de Santafé recibía fondos de diversas oficinas diseminadas en un radio amplio de acción; sin embargo se muestran bastante dispersas y corresponden fundamentalmente a las provincias de Tunja y Santafé, lo que cambiaría ostensiblemente al final del siglo, sobre todo por la creación de nuevas rentas y la instauración de más oficinas recaudadoras.

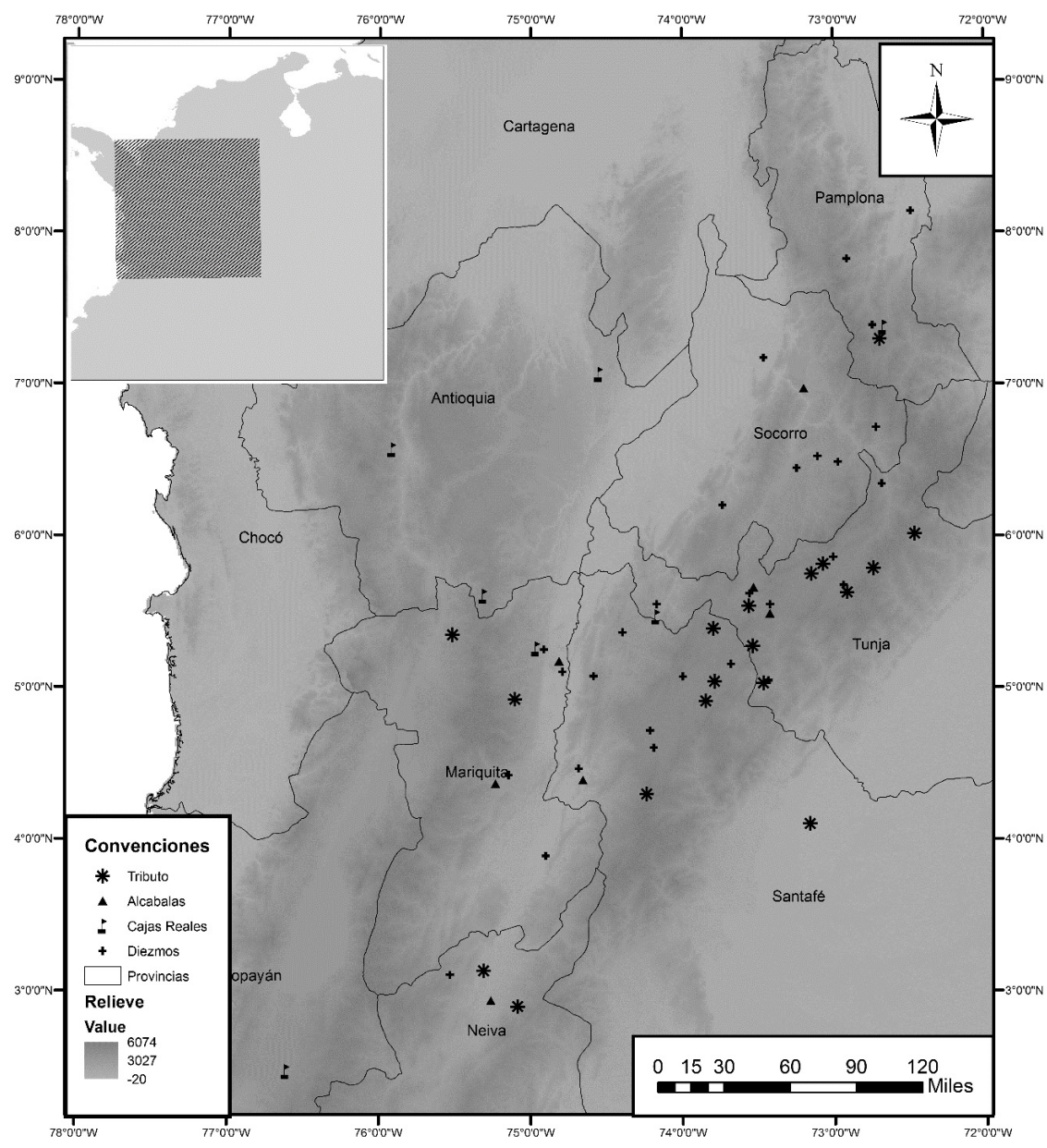

MAPA 1.

Oficinas de recaudo donde se originaban los fondos de la caja real de Santafé en 1705.

Fuente: Terreros, 1792 y Varela, 2018.

Por Real Orden del 21 de junio de 1790 Pedro López de Lerena (López, 1790) pidió al Tribunal Mayor de Cuentas de Santafé la formación de relaciones exactas de cada uno de los ramos propios de la Real Hacienda, con expresión puntual de su importancia, modo de recaudo, nombre de los encargados, valor entero anual, número de empleados, sueldos, cargas de cada ramo, producto de cada caja y el partido que comprenden las cajas matrices, manifestando las distancias y método para hacer los enteros entre unas y otras. ${ }^{3}$ A la par de ello, el Virrey José Manuel de Ezpeleta auspiciaba los esfuerzos para que Joaquín Durán y Díaz, quien se desempeñaba como Capitán del Batallón de Infantería y Auxiliar de Santafé, llevara a término la empresa de componer una guía para comerciantes y forasteros sobre el Nuevo Reino de Granada (Deas, 2012). 
Ambas empresas dieron frutos. En 1792 los oficiales reales de Santafé enviaron al Virrey el Manifiesto por relaciones y estados de los ramos de la Real Hacienda que se administran en esta tesorería de Santafé de Bogotá, formado en cumplimiento de la real orden de 21 de junio de 1790 y con arreglo al papel de advertencias prescriptas al intento por el excelentísimo señor virrey en 16 de octubre del mismo año (Caja Real de Santafé, 1792) relación que sirve a los objetos del presente artículo, toda vez que los encargados manifestaron el objeto y alcance de ella en los siguientes términos:

El objeto de las relaciones, se reduce, a dar la de cada uno de los definidos ramos reales fundamentales y fijos. Declárese en pos de su narración histórica, los productos, pensiones, gastos peculiares, y líquidos en sus deudas activas: seguirán luego las relaciones de las cargas situadas sobre la Real Hacienda en común.(Caja Real de Santafé, 1792).

Para tal fin, los encargados diseñaron un completo cuadro no solo de los productos, sino que también dieron cuenta de todas y cada una de las oficinas que recaudaban y enviaban sus fondos con destino a la caja matriz. A la par de ello, Joaquín Duran y Díaz en 1794 logró completar la información contenida en el anterior ejercicio de los oficiales reales (Durán, 2012). Ambas obras permiten determinar la totalidad de las oficinas que enviaban sus fondos a Santafé por concepto de estancos, alcabalas, tributos, venta de oficios y quintos; y no solo el de los sobrantes de las cajas reales, ejercicio que ya había sido emprendido con anterioridad (Pinto, 2016a), información que de manera gráfica se evidencia en el MAPA 2.

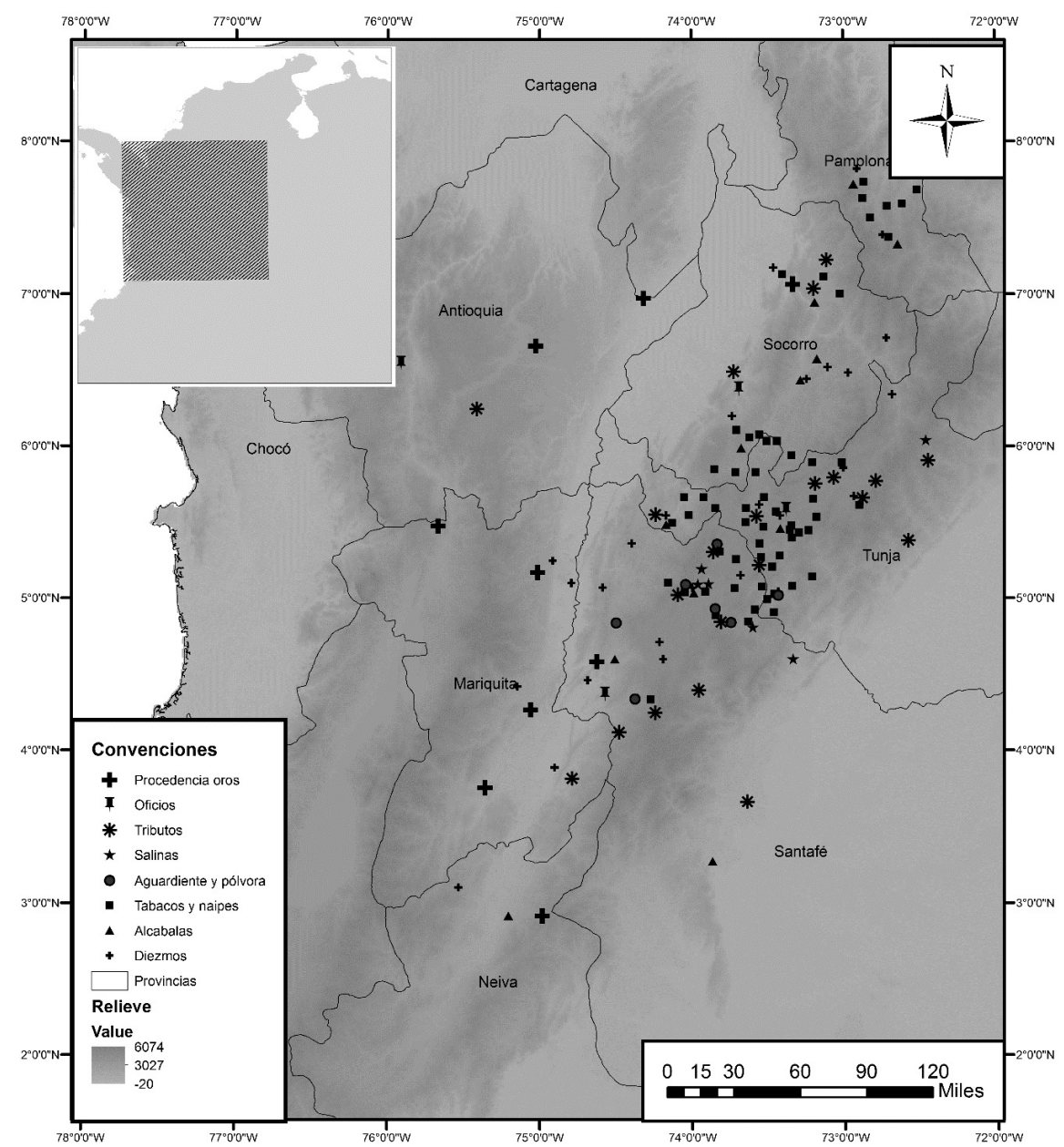

MAPA 2

Oficinas de recaudo donde se originaban los fondos de la caja real de Santafé en 1793.

Fuente: elaboración propia con base en Durán, 2012 y Caja Real de Santafé, 1792 y Varela, 2018. 
Si se toma en cuenta solo las cajas reales que remitieron sus fondos hacia Santafé tendríamos una estructura mucho más simplificada, que en esencia incluiría solo las 14 principales con las que contaba el Virreinato, pero tomando en cuenta que la Real Hacienda tenía un carácter mixto (Sánchez, 2016, p. 91) conformado por distintas colecturías particulares dedicadas al recaudo de ramos específicos (alcabala, diezmos, salinas, tributos, remisión de oros para quintar, tabaco, aguardiente, naipes pólvora), la situación se hace mucho más compleja.

Tomado en cuenta lo anterior, el MAPA 2 muestra la existencia de por lo menos 150 despachos encargados del recaudo de diversos fondos con destino a la caja de Santafé, evidenciando las razones por las cuales los estancos se convirtieron en pieza clave de su recaudo; esto no acontecía en 1705 como se vio en el MAPA 1, ya que en 1793 son oficinas de nuevas rentas instauradas, de las cuales pertenecen 74 a los tabacos, 8 al aguardiente y 7 a la sal. Igualmente, en 1793 las alcabalas eran administradas por 13 oficinas y no 7, los tributos por 24 en distintos poblados y la venta de oficios incluía los de Antioquia, Tocaima, Tunja y Vélez. Ello hace evidente como la casi totalidad del centro del Virreinato estaba atravesada por una abigarrada red cuyo punto nodal estaba en la caja matriz, espectro que se amplía incluyendo el occidente, si se toma en cuenta la procedencia de los oros para quintar y las cajas principales de otras provincias que remitían sus sobrantes, de las cuales solo incluimos las que remitieron con mayor constancia durante todo el periodo con base en los sumarios de cargo.

Lo anterior nos permite concluir que el reformismo en el ámbito fiscal para la caja real de Santafé, marcado por la centralización y la estatización de algunas actividades productivas (estancos), no solo provocó el aumento del número de ramos, sino que además requirió un proceso de densificación de las oficinas recaudatorias que permitían un control más directo sobre cada una de las poblaciones y actividades a ser gravadas. Así las cosas en términos territoriales la jurisdicción de la caja se amplió, centralizó y densificó, lo cual indudablemente impactó en los niveles de recaudo.

\section{Nuevos RAMos Y MÁS OfiCINAS. El RETo DEL RECAUdo Y LA ADMINiSTRACión}

Hasta el momento se ha constatado cómo el reformismo borbónico afectó la cantidad de ramos recaudados por la caja de Santafé y el territorio de su jurisdicción; en la presente sección, intentaremos hacer un acercamiento al reto que implicarían en términos administrativos ambos fenómenos. Primero daremos cuenta de un panorama general de la situación en 1747, después se expondrán cuáles fueron los ramos que aparecieron, y por último se describirán los cambios en su cobro.

Poco se sabe de la administración de la Real Hacienda durante el mandato del Virrey Eslava debido a que no dejó escrita una relación de mando; de hecho la que se conserva fue redactada seis años después de finalizado su periodo por el oidor Antonio Berastegui en 1751, en la que solo se hace una breve descripción del gobierno del Real Erario (Giraldo, 1954). A pesar de lo anterior, existe un valioso documento escrito por el contador mayor del Tribunal de Cuentas de Santafé en 1747. Se trata de un completo informe sobre la situación de la Real Hacienda del recientemente fundado virreinato de la Nueva Granada, producto de la orden de 4 agosto de 1746, emitida por el virrey, con el fin de establecer en qué puntos sería factible la aplicación de la ordenanza de intendentes de provincias y ejército emitida en julio de 1718 para España, en lo concerniente al real erario neogranadino. Este documento nos permitió dar un vistazo a la difícil situación que enfrentaban las autoridades para el manejo de la hacienda y así poder ponderarlo con el panorama que se ofrece a fines de siglo.

López y Campaña describió un panorama desolador debido al escaso control sobre los encargados del recaudo de diversos rubros. Por ejemplo, frente a los quintos de oro denunció que no eran puntual ni correctamente recaudados en el Chocó (principal zona de producción del metal), y propone como innovación el que los recaudadores formen libros anuales donde se sienten las cantidades que salen de las lavadas, enviando dichos informes junto con los oros a las cajas reales semestralmente, lo que sugiere que no 
lo hacían o que lo efectuaban con espacios de tiempo más dilatados. Algo similar sucedía con los naipes, ya que los oficiales reales solo se encargaban de vender los pocos que les llegaban, sin ningún reparo en controlar el contrabando una vez terminada la oferta (López y Campaña, 1747).

Además de ello, el contador muestra su gran preocupación por lo que consideraba una intervención abusiva de la iglesia en la cobranza de algunos ramos. Tal es el caso de los novenos, que según López eran rematados de manera subrepticia a través del uso de redes clientelares, en las cuales los jueces estaban unidos por lazos de amistad con los curas, cediendo a estos últimos los contratos con bajos precios, razón por la cual se proponía prohibir que los clérigos pudiesen participar en las pujas o arrendar los ramos a su nombre o por interpuesta persona. Similares abusos eran denunciados por el contador en algunos partidos foráneos de la caja de Santafé, ya que distintos sacerdotes se apropiaban de los arrendamientos de tierras y pulperías. Por si fuera poco, en su informe se denunció que algunas comunidades no pagaban alcabalas ni diezmos de propiedades religiosas, cobijadas en el permiso para no cancelarlas por ser bienes que estaban exentos como parte de las dotes iniciales con las cuales habían sido establecidas. Ante ello, propuso como correctivo la necesidad de hacer un inventario de los bienes que hicieron parte las fundaciones de cada comunidad, para determinar cuáles de ellas habían sido adquiridas con posteridad y así cargar sus transacciones y productos con los gravámenes correspondientes (López y Campaña, 1747).

Frente a otras rentas los desórdenes y abusos eran constantes. Ejemplo de ello es la venta de oficios, cuyos resultados no son óptimos debido a que muchas veces no existen postores, mientras que los corregidores defraudan en el cobro de tributos, ya que necesitan cubrir los costos de trasporte para su recaudo, por lo que se propone arrendarlos. Por otra parte, López y Campaña no se muestra ajeno ante lo que según él a futuro se podía constituir en una importante fuente de ingresos: los estancos. En efecto, el contador propone la creación del de la pólvora debido a la ampliación de su consumo, el riesgo en su trasporte y la suficiente disposición de recursos para su fabricación.

Frente al monopolio del tabaco el proyecto del oficial real apunta a su extensión a todo el virreinato a través de arrendamiento, pregonando con distinción el de humo y el de polvo; visión que anticipó la del Virrey Flórez y el Visitador Gutiérrez de Piñeres, ya que buscaba que cada cosechero declarara su producción ante el juez de cada partido, emitiéndose una guía para su extracción con el fin de que el producto fuera vendido solo al estanquero, quien emitiría una tornaguía para el control del contrabando. Por otra parte, el contador planteó la posibilidad de que la venta de mieles se restringiera única y exclusivamente a los estanqueros. Tan amplias eran las expectativas de López sobre los estancos, que llegó a proponer la reducción de los juros que pesan sobre la Real Hacienda del $5 \%$ al 3\%, ya que su pago sería más expedito con base en los sobrantes de los estancos, lo cual beneficiaba a su parecer a los acreedores pues serían canceladas las deudas a su favor atrasadas desde hacía varios años (López y Campaña, 1747). Varias de estas propuestas fueron retomadas en la segunda mitad del siglo como lo veremos a continuación.

La primera forma de afrontar varios de estos inconvenientes y asumir algunas de las propuestas del fallecido contador, la constituyó la orden de cobrar y manejar algunas rentas por parte de la caja, así como la creación de otras. Podemos elaborar una pequeña cronología con arreglo al informe presentado por parte de sus oficiales al Regente Visitador Gutiérrez de Piñeres en 1778, dando cuenta de algunas de estas novedades. Así, para la década del 50, momento en el cual el Márquez de la Ensenada desplegaba todo un conjunto de reformas en la Hacienda Real para el conjunto imperial (Dubet, 2016), la caja asumió la administración de los sobrantes de diezmos en calidad de depósitos, incorporó el cobro de arrendamiento de tierras de resguardos y del gravamen de camellón que consistía en el pago de un real por carga de efectos de Castilla y de la tierra que ingresaran a la ciudad (Restrepo, 2009, p. 180). En la del 60 se estableció la fábrica de pólvora cuyos productos eran parte de los cargos de los oficiales de la caja, se sumaron los beneficios del laboreo de minas de esmeraldas, se implantó la renta del tabaco en hoja y las temporalidades de los bienes de los jesuitas expulsados. Por último, en la del 70 se adjuntaron los rendimientos de la explotación de las minas de sal y de los fondos de seminario, que consistían en el 3\% de los siete novenos restantes después de descontar los dos novenos del rey; de la 
masa recaudada de los diezmos de la cual previamente se habían extraído el 50\% de cuarta capitular y cuarta episcopal (Caja Real de Santafé, 1792).

Pero los cambios no solo involucraron la creación de nuevos ramos o la adjudicación de los mismos a la caja, pues incluyeron la variación en los mecanismos de recaudo, la forma de administrar los fondos y los procedimientos de vigilancia y control a las operaciones contables. Algunos de estos cambios serán abordados a continuación.

Las autoridades virreinales detectaron varios problemas frente al cobro de las alcabalas en Santafé en 1778, a saber: los conflictos acaecidos por el arrendamiento de su administración entre el cabildo y el comercio, la falta de claridad en las alícuotas que disponían su recaudo y la multiplicidad de nombres con los cuales se ejerció el cobro (Caja Real de Santafé, 1778). Como medidas para mitigar estos inconvenientes se creó en el año de 1750 la aduana de Santafé, encargada del cobro de este derecho más el de camellón, determinándose que también dicha oficina funcionaría como principal expendio de papel sellado, otorgando el 6\% de premio para los vendedores, arreglo que se administró con base al cobro de un premio del 2\% por parte del administrador (Restrepo, 2009, p. 130). Posteriormente, la principal reforma se llevó a cabo en 1780 gracias a las gestiones del Regente Visitador Francisco Gutiérrez de Piñeres, quien redactaría la instrucción para su recaudo, instauraría la administración principal con sede en la ciudad y clarificaría el cobro de la misma bajo un solo nombre.

La instrucción de Gutiérrez (1792) estableció el reglamento para el pregón y arrendamiento de la renta en las colecturías particulares, las cuotas y los productos sobre los cuales recaía, el procedimiento de su cobro, la distinción de aquellas provenientes de censos y contratos, además de determinar el sistema de guías y torna guías para su efectivo control. Al mismo tiempo se creó la administración principal de Santafé, instancia dirigida de forma directa por la corona a través del nombramiento de oficiales reales que se encargaron del recaudo de los fondos provenientes de los distintos partidos, para que con ellos sufragaran sus gastos, y cuyos productos irían a la caja real de Santafé; además de ello debía colectar las cuentas de todas ellas y elaborar la suya propia, con el fin de que fueran revisadas y fenecidas por el Tribunal Mayor de Cuentas (Administración de Alcabalas de Santafé, 1802). Así las cosas, se pasó de un trato directo de los partidos foráneos con la caja real y con el Tribunal de Cuentas, a un trato indirecto mediado por las labores de la administración principal, lo cual mejoró el control al descargar de la revisión de todas las cuentas de los partidos foráneos al Tribunal Mayor de Cuentas.

Las bulas también se constituyeron en objeto de reforma ya que su administración hasta 1790 estuvo a cargo de un administrador particular. A partir de ese momento pasó a la potestad de los oficiales de la caja real de Santafé, por lo que su cobro quedó a cargo de los sacerdotes y comisarios de cada partido, quienes descontaban el $6 \%$ de premio y el $10 \%$ por gastos de conducción, remitiendo el sobrante y sus cuentas para ser revisadas a la caja real. Por su parte, la caja cubría con estos ingresos algunos réditos de juros y los gastos de distintas misiones religiosas, obligándose a informar al tribunal del ramo (como ente contencioso superior sobre las colecturías particulares) los pleitos que se producían al respecto (Caja Real de Santafé, 1792).

La minería (fundamentalmente del oro) y el cobro de los impuestos sobre su producción también sufrieron importantes trasformaciones. En una primera instancia, los quintos fueron reducidos al 3\% por Real Orden de 1 de marzo de 1777; además de ello se estableció en 1779 el cobro de este derecho por un 18\% a los labradores independientes de manera artesanal. Desde 1778 se ordenó administrar de forma directa el cobro de derechos de fundición, estableciendo como tarifas 2 reales por cada marco de plata, 5 reales por cada castellano de oro y 4 reales por cada castellano de platina en cada una de las oficinas de fundición (Caja Real de Santafé, 1792). A la par de ello, se eliminó el sistema de arrendamiento para el manejo de las casas de moneda, oficinas que para 1751 pasaron a administración directa en Santafé y la de Popayán en 1769, cuyos productos líquidos se enviaban a la caja real de su jurisdicción y sus cuentas al Tribunal Mayor. Esta iniciativa fue impulsada por el contador Ortiz de Landázuri desde la metrópoli para el conjunto de las casas de la moneda dispersas en el territorio americano, como lo demuestra Dubet en este monográfico. 
La renta de diezmos también fue pieza clave del andamiaje de la reforma administrativa debido a la importancia de los dos novenos reales en la gruesa de los ingresos de la caja real. En efecto, la amplia red de encargados a nivel local incluía a los diezmeros y a los jueces de cada partido, quienes estaban obligados a enviar sus cuentas y fondos al juzgado de diezmos de Santafé, instancia que luego de descontar los gastos y efectuar la distribución de la masa decimal remitía los novenos del rey a la caja de Santafé (Caja Real de Santafé, 1792).

Igual importancia tenían los tributos de indios, razón por la cual se reorganizaron los pueblos tributarios a fines de la década del 70 (González, 2005, p. 64). El cobro de este gravamen fue sumamente confuso y se tasó con arreglo a la productividad de las poblaciones, con una oscilación entre 2 y 9 pesos plata anuales por cada indígena hombre en edad laboral, además de 4 pesos por cada indígena fugado de sus comunidades y 17 reales por aquellos considerados reservados (ejercían el cargo de caciques, gobernadores, tenientes, alcaldes, capitanes, sacristanes, doctrineros y enseñantes de la doctrina cristiana). Para 1792 la mayor parte del tributo fue recaudado en plata, sin embargo se mantenía la costumbre de efectuarlo en especie (mantas de algodón, de lana, alpargates, casabe, maíz, sombreros y gallinas) obligando a los colectores a vender dichos productos para enviar el importe en efectivo, mientras que solo en seis pueblos se recaudó en oro a razón de 3 castellanos por cabeza (Caja Real de Santafé, 1792).

A esta variedad de tasas y especies de recaudación se sumó el mantenimiento de la costumbre de hacer su cobro en dos contados: la demora en el primer semestre del año y el requinto en el segundo, siendo exentos del primero las poblaciones de tierra caliente, sumas de las cuales se extraía el pago de los curas doctrineros, sacristanes, protectores de indios, encomenderos, corregidores y administradores del ramo, quedando el líquido sobrante remisible a la caja. Por otra parte, el recaudo se hizo a través de dos métodos: por arriendo y a cargo de los gobernadores y corregidores de cada pueblo, siendo las remisiones más importantes una vez deducidos los gastos las de los partidos de Coyaima, Turmequé, Gamesa, Ubate, Guatavita, Zipaquirá, Casanare y Tamara (Caja Real de Santafé, 1792).

Sin embargo, dichas remisiones no constituyen el total del importe que registra la caja de Santafé por el ramo debido a que, como es notorio, de los fondos de tributos en cada uno de los pueblos se descontaban cantidades que debían ser asumidas por las rentas de diezmos, toda vez que pertenecían a los gastos propios del culto. ${ }^{4}$ Lo anterior implicaba que los oficiales de la caja real descontaban parte de la gruesa de diezmos y se la agregaban a las remisiones que se daban por tributos, suma cuyo producto era registrado bajo el cargo del ramo de la contribución indígena. Por esta razón los oficiales proponían que, aunque la práctica fuese mantenida, a la hora de llevar la contabilidad se especificara qué parte pertenecía a los novenos y cuál a los tributos (Caja Real de Santafé, 1792).

Además de interesarse por recuperar los gastos eclesiásticos que se efectuaban con rentas reales, también las autoridades se preocuparon por recuperar los fondos de las exenciones al pago de tributos que gozaron los indios que se desempeñaban como sacristanes, también a través de los novenos ajenos al Rey:

Aplicase también a dicho medio noveno al fondo de tributos, por haberse prevenido en decreto de 14 de noviembre de 1780, así se ejecutasen compensación del tributo que se condona, o pasa al indio que ejerce el oficio de sacristán en cada pueblo, bien que el medio noveno de la mayor parte de sacristanes por lo común excede del valor del tributo de los tales indios, y con todo tácitamente está mandado aplicar su total a la Real Hacienda, por junta de tribunales, y también hay varias sacristías que su medio noveno no alcanza a cubrir el tributo del sacristán, y otras hay que exceden en dos o tres tantos, y bajo de este supuesto, se aplican al citado fondo 1.283 que montó el referido medio noveno (Caja Real de Santafé, 1792).

En virtud de ello, las autoridades reales en Santafé no solo reorganizaron los pueblos de indios, sino que puntualizaron el cobro del tributo, procurando la recuperación de los gastos eclesiásticos y de doctrina en cada pueblo a través de la gestión de novenos ajenos al rey provenientes de la masa decimal. Así, el ramo de tributos incluyó el importe del cobro de la contribución a los indígenas de cada partido, los pagos efectuados al culto (restituyendo al rey lo tomado para tal fin de los novenos) y las exenciones de los indios con diversos cargos. 
Las autoridades también centraron su atención en la posibilidad de extraer utilidades fiscales del laboreo de la sal. Así fue como entre 1760 y 1777 el ramo se constituyó en un rubro propio de las cajas reales de Santafé, pues con anterioridad el establecimiento fue de uso libre común (Sánchez, 2014), pasando a ser administradas de manera directa a través del monopolio desde 1777 las salinas de Zipaquirá, Tausa y Chita. Quedó excluida de esta medida la salina de Nemocón que pertenecía a los indígenas bajo la figura de domino eminente, lo que obligó a las primeras a pasar su líquido producto a la caja real una vez descontados los gastos de leñas, lozas, horneros, cargadores, picadores, además de los sueldos de administradores, contadores, corregidores y guardas (Caja Real de Santafé, 1792).

Indudablemente en este marco es imposible no referirse a las rentas estancadas, especialmente las del aguardiente y del tabaco. La primera de estas fue establecida en el Virreinato de la Nueva Granada definitivamente en el año de 1736 a través del sistema de arriendo, en el cual se adjudicaba su manejo a un particular encargado de expedir las licencias para su fabricación; posteriormente se implementaría el sistema de asiento a través del cual el administrador por remate se hacía con el derecho de cobro sobre las botijas fabricadas descontando un porcentaje a su favor (Mora, 1988, p. 20). Por último, la administración directa del ramo fue ganando terreno entre 1760 y 1776, hasta que se estableció su definitivo arreglo bajo esta modalidad, gracias a la instrucción de Gutiérrez de Piñeres que fundaría la Administración Principal de la renta con sede en Santafé, teniendo las funciones de tribunal encargado de su manejo, control y mejoramiento; fiscalizando las operaciones del expendio de mieles, su fabricación y distribución a través de estancos y estanquillos. Así las cosas, cada administración principal veló por la recaudación de sus productos y el cubrimiento de los gastos propios de la fabricación y distribución, obligándose a enviar sus cuentas y fondos a la Administración Principal, lugar en donde se descontaban los gastos de su funcionamiento, remitiendo el líquido producto a la caja real de Santafé (Gutiérrez, 1779).

Por otra parte, la renta del tabaco fue establecida en 1744, y hasta 1778 se desarrolló un primer momento caracterizado por el remate del arriendo del monopolio de la comercialización del producto (González, 2005, p. 77). Posteriormente, bajo los auspicios del Virrey Flórez y el Regente Visitador Gutiérrez, se logró el establecimiento de su gobierno directo en la totalidad del territorio, gracias a la instauración de la Administración Principal del ramo en Santafé. Así las cosas, cada administración particular determinó los distritos de siembra y compra del tabaco a los cosecheros, para luego ser enviado a las factorías en donde la hoja era reenviada a las administraciones y de allí remitida a los distintos estancos. Cada una de las administraciones particulares enviaba sus cuentas y fondos a la Administración Principal de Santafé, en donde al igual que con la de aguardiente se remitía su líquido producto a la caja real (Torres, 2016). Es preciso aclarar que la administración de la capital solo expendía tabaco en hoja para fumar y en polvo para aspirar, último que provenía del exterior ante la baja calidad del producido en el virreinato (Torres, 2016, p. 18).

Este recorrido deja ver cómo el reformismo impactó en la administración y el cobro de los ramos de la Real Hacienda en Santafé. Por lo menos desde la década del 40 el tribunal mayor de cuentas era consiente de algunos de los problemas que aquejaban al fisco virreinal, tales como la falta de control al no conocerse cifras puntuales de la producción de oro, la intervención del clero para sacar beneficio del remate de algunas rentas y la evasión por parte de distintos sectores. Ante ello, se proponía un mayor control de las actividades fiscales. Así las cosas, se pasó paulatinamente a un modelo en el cual se privilegiaba la administración directa de las rentas por parte de funcionarios y la creación de nuevos gravámenes.

El impulso reformador se materializó en el manejo de las rentas en dos periodos. El primero de ellos corre entre 1750 y 1769 , momento en el cual se implementa un modelo que privilegia la centralización en la administración de los dineros colectados y enviados a la capital, con el arrendamiento de su recaudación otorgado a particulares a través de remate, además de la creación de distintos rubros (camellón, pólvora, tabaco, temporalidades y aguardientes). Posterior a ello nos encontramos con un modelo donde se privilegia la administración directa tanto en la centralización como en el recaudo en cada una de las localidades, proceso que ya había dado sus primeros pasos con la casa de la moneda de Santafé en 1751, pero que se consolida 
con la de Popayán en 1769 y con la creación de las administraciones principales de alcabalas y la de rentas estancadas. Así las cosas, el reformismo no solo se acompañó con la creación de nuevos ramos, sino también con la consolidación de un modelo de gestión directa de cada uno de ellos, haciendo necesaria la apertura de nuevas oficinas exactoras, lo que se materializó en una densificación de las mismas en el territorio virreinal. Como apenas era de esperarse, todo ello estuvo acompañado de la implementación de nuevas formas de control y vigilancia a las instancias recientemente instauradas, como se verá en la siguiente sección.

\section{Organismos de CONTROL DE LAS OPERACiONES FISCALES EN SANTAFÉ}

Desde 1605 el Tribunal Mayor de Cuentas de Santafé fue el órgano rector de la vigilancia de las operaciones fiscales en la Audiencia, ya que fue encargado de recibir, tomar y fenecer las cuentas de las distintas cajas, quedando sus contadores obligados a cobrar de forma coercitiva los alcances a los respectivos oficiales reales a través de órdenes de prisión o de venta de bienes. Sin embargo, en caso de presentarse reclamaciones sobre los alcances los contadores estaban obligados a compulsar copias y reunir pruebas a fin de ser enviadas al Presidente de la Audiencia, quien debía nombrar una junta para que cuatro oidores de la Real Audiencia decidieran el caso; en esta junta los contadores del tribunal solo tenían carácter consultivo (Rojas, 2001, p. 48).

A la par de ello, se instauró la Junta de Hacienda en 1627, la cual tenía como principal función el tratamiento de los pleitos de Real Hacienda cuando existiere recusación a todos los contadores y para la aprobación de gastos extraordinarios (Rojas, 2001, p. 74). Los términos de su fundación fueron

Mandamos que en todas nuestras Audiencias se haga una junta, y acuerdo de hacienda precisamente cada semana, los martes, miércoles o jueves por la tarde, eligiendo el día más desocupado, en que se trate de nuestra Real Hacienda, y pleitos fiscales, y en ella asistan el Virrey, o Presidente, y el Oidor más antiguo, Fiscal, contador de Cuentas, donde hubiere Tribunal, y el oficial real más antiguo (Recopilación de Leyes de los Reinos de Indias, 1681).

Como bien lo señala Rojas (2001), esta estructura sufrió pocos cambios durante el siglo XVII. Sin embargo, para el XVIII hemos rastreado profundas trasformaciones, materializadas en la instauración de la Superintendencia de Hacienda, las Administraciones de Rentas Estancadas, la creación de la Junta Superior de Real Hacienda y la aplicación parcial del sistema de intendencias en la Nueva Granada en lo concerniente al plano contencioso y administrativo en materias de Real Hacienda. A continuación pasaremos a referenciar cada una de estas trasformaciones.

Por real orden de 30 de junio de 1751 dada en Aranjuez, a tono con las reformas para el conjunto de los virreinatos emprendidas por el Márquez de la Ensenada (Dubet, 2016), se le otorgaron al Virrey de Santafé las facultades de Superintendente de Real Hacienda, dando potestad a este como encargado de la vigilancia y la toma de medidas necesarias para el mejoramiento de los recaudos (Somodevilla, 1751).

De esta manera se establecía al Virrey como máxima figura de la administración del Real Erario, disminuyendo el poder de la Audiencia en la materia, ya que aunque esta última mantenía su papel contencioso en la determinación de los pleitos y de asesora en la Junta de Hacienda, la decisión última corría a cargo del Superintendente. Esta medida estaría en plena concordancia con la intención de sustraer poder a las corporaciones colegiadas del manejo de la hacienda, con el fin de establecer un ejercicio de administración más afianzado en la vía ejecutiva, previamente robustecida tras la institucionalización de la vía reservada como mecanismo de comunicación directo entre los virreyes y los ministros de la metrópoli, dejando a un lado la intervención de las audiencias y el Consejo de Indias en materia hacendística (Dubet, 2016).

Reforzando la anterior idea y en aras de un gobierno más equilibrado y eficiente, en la Nueva Granada se establecieron las administraciones principales de rentas estancadas en 1779 , una de tabacos y naipes y otra de aguardientes y pólvora, inhibiendo de la vigilancia de las cuentas de dichos rubros al Tribunal Mayor de Cuentas, ya que ambas instancias sirvieron como tribunales en donde los nuevos oficiales reales fenecían las 
cuentas, pasando los pleitos directamente a la Superintendencia, quien en última instancia daba concepto sin intervención de la Real Audiencia. Cada una de estas estaría compuesta por un director, un contador, un oficial mayor, un oficial segundo y uno tercero (Gutiérrez, 1779). Frente al trámite de los reclamos por las cuentas, las instrucciones dadas a los contadores de las administraciones generales al respecto son claras, al determinar las funciones de estos, descontando la participación de la Real Audiencia y el Tribunal de Cuentas en la materia (Gutiérrez, 1779).

En la práctica el mantenimiento de dos tribunales independientes resultó demasiado costoso, lo que llevó en 1780 a la instalación de un solo tribunal bajo la denominación de Dirección General de Rentas Estancadas, compuesta por dos contadurías que coincidían con las dos administraciones (tribunales) anteriormente diseñados. Se mantuvo la independencia de la Real Audiencia y el Tribunal Mayor de Cuentas, aunque en esta oportunidad la resolución de los pleitos no recayó exclusivamente en el Virrey como Superintendente de Real Hacienda, sino en una Junta de Rentas Estancadas conformada por el superintendente (virrey), el director del nuevo tribunal y los dos contadores mayores de cada renta, enviando sus cuentas directamente a la metrópoli y sus productos líquidos a la caja real de Santafé (Gutiérrez, 1780).

La estocada final al poder del gobierno colegiado en el manejo de la Real Hacienda se dio como producto de la adopción de la instrucción para el cobro de Alcabalas anteriormente citada y que fuera escrita por Francisco Gutiérrez en 1780. Esta no solo reorganizó la administración del ramo sino que inhibió de tratar cualquier pleito en la materia a la Real Audiencia, ya que estableció la creación en cada provincia de un subdelegado de la Superintendencia de Hacienda como juez de primera instancia en cada pleito, el cual estaba supeditado de forma directa a la superintendencia como instancia definitiva en los reparos (Gutiérrez, 1792, p. 99), medida que fue ampliada a los demás ramos de Real Hacienda.

Posterior a ello, se estableció como máximo tribunal en causas del Erario Regio a la Junta Superior de Real Hacienda, instaurada en 1797 como organismo consultor para la toma de medidas en la materia y para el ejercicio de gastos extraordinarios, conformada por el Virrey como Superintendente General, el Regente, un Oidor, un Fiscal de la Audiencia, el Ministro más antiguo del Tribunal de Cuentas y el contador o tesorero de la caja real (Ots Capdequí, 1946, p. 99). Así las cosas, ya la Real Audiencia y sus ministros no eran los únicos que tomaban las decisiones contenciosas con base en el voto consultivo de los oficiales del Tribunal de Cuentas, ya que estos tendrían parte decisoria junto al Virrey. Este complejo panorama nos lleva a afirmar que, contrario a lo afirmado por varios de los trabajos más representativos sobre la Real Hacienda y las reformas borbónicas en la Nueva Granada (Phelan, 1980, p. 278 ; McFarlane, 1997, p. 328; y Navarro, 1995, p. 46), el sistema de intendencias sí tuvo aplicación en el Virreinato al menos en el plano contencioso y de administración de la Real Hacienda a nivel municipal, como lo demuestra el hecho de que la mayor parte de las rentas se manejó bajo los principios de la Ordenanza de Intendentes de Nueva España.

Como demostración de lo anterior no tenemos mejor recurso que las propias palabras del Virrey Amar y Borbón, quien dirigiéndose a la Real Audiencia en 1806 a través de un decreto ordenando abstenerse de juzgar sobre casos pertenecientes a la Real Hacienda, hace un completo recuento de la aplicación de la ordenanza de intendentes en suelo neogranadino:

Desde que llegó a esta capital la real orden de 24 de abril de 1787, se mandó en su obedecimiento guardar y cumplir la Real Ordenanza de Intendentes de México en lo que no fuere inadaptable, y que para el efecto se pasaron los ejemplares necesarios a los Tribunales de Real Hacienda que se han gobernado y gobiernan por ella, como también las juntas generales de diezmos de todo el reino, resultando así mismo que por la instrucción, o reglamento general de Real Hacienda formado para el Virreinato en doce de octubre de 1780 aprobado por su majestad en Real Orden de 4 de agosto de 1781, y publicado y obedecido en seis de marzo de 1782, aun antes de que se remitiera la Real Ordenanza de intendentes, ya estaba por él inhibida la Real Audiencia de conocer en causas de hacienda, pues por el artículo primero parágrafo veintiuno, se mandó que en cada provincia y sus agregados, se nombrara como se nombró un subdelegado de la superintendencia general del reino que con jurisdicción privativa conociera de cuantos negocios judiciales y contenciosos se llevaran en toda la extensión de su territorio, que de cualquiera manera pertenezcan a los referidos o tengan con ellos incidencia o conexión; cuyas subdelegaciones equivalen a las intendencias de provincia por lo menos en lo respectivo a la Real Hacienda, y por el artículo sexto del parágrafo veintidós en que se trata de las causas criminales y civiles que se sigan por fraude o contravención a las 
reglas allí establecidas, se motivó que en unas y otras, procedan aquellos admitiendo las apelaciones para la superintendencia general, y no para otro tribunal, ni juzgado alguno (Amar, 1806).

Esta extensa cita nos permite dar cuenta del avance del gobierno ejecutivo sobre la Real Hacienda en la Nueva Granada, pero también nos invita a abrir nuevos campos de indagación en los cuales en lugar de preguntarnos las razones por las cuales no se aplicó el sistema de intendencias, aduciendo razones políticas como la desaparición física de ministros reformadores en la metrópoli (Navarro, 1995), el desorden social producto de la rebelión de los comuneros (Phelan, 1980) o la caída de los ingresos de la Real Hacienda (Pinto, 2016a), nos obliga a profundizar sobre el funcionamiento de dicha institución en materias puntuales como la expuesta. Por el momento, las palabras del Virrey dejan claro como paulatinamente el gobierno de la Real Hacienda pasó a ser una preocupación de funcionarios reales y no de órganos de gobierno colegiado, lo cual no estuvo lejos de sobresaltos como los que analizaremos a continuación.

Dos instituciones sintieron con mayor rigor las nuevas obligaciones que implicó la creación de nuevos ramos, la ampliación de la red de recaudo y la reorganización del gobierno de hacienda. Nos referimos al Tribunal Mayor de Cuentas que, a pesar de ser eximido de la vigilancia de las cuentas de cuatro rentas (tabaco, naipe, aguardiente y pólvora), y de varias cajas tras la creación del Tribunal de Cuentas de Quito en 1776, se quejaba de la falta de funcionarios y de lo envejecida de su planta. La otra instancia está constituida por la caja real de Santafé, cuyos oficiales vieron multiplicadas sus funciones tras el nuevo sistema de administración.

Para 1788 los funcionarios del Tribunal Mayor de Cuentas mostraban un panorama desesperado al Virrey Caballero y Góngora. Según estos, su oficina no era atendida por la cantidad de empleados que requería, por lo cual comparaban su planta con la de sus similares del Perú y Nueva España, quienes contaban con 20 y 25 oficiales, mientras que el de Santafé solo contaba con 7, suprimiéndose 3 en 1778, que llevaban a cabo los trabajos de informar y revisar todas las cuentas de las cajas reales del virreinato que para entonces llegaron a 19 (Tribunal Mayor de Cuentas de Santafé, 1788). Además de ello, los contadores que quedaban estaban muy viejos y sus funciones solo podían ser pobremente desempeñadas (Tribunal Mayor de Cuentas de Santafé, 1788).

La solución de los propios funcionarios no era otra que nombrar 4 contadores mayores, 2 más de "resultas" y 2 “entretenidos", misma que sería acogida por Real Orden en 1790. Así quedó conformado el tribunal en 1794 por 4 contadores mayores, 5 ordenadores, 2 oficiales, 1 escribano y 1 portero (Durán, 2012), además de continuar descargado de la vigilancia de las rentas estancadas y de las cuentas de las cajas de Quito, Guayaquil y Cuenca.

Pero indudablemente el mayor peso de la reforma recayó en los hombros de los oficiales de las cajas reales de Santafé, ya que al ser matriz y al ampliarse su red de recaudo, como se vio en el MAPA 2, se encontraron obligados a fenecer en primera instancia varias de las cuentas de los nuevos ramos creados, o de los antiguos cuya administración se había trasformado. Una imagen palpable de dicha carga es expuesta por los oficiales de la caja en representación al Virrey en 1805, enviada en contestación de los reparos que hacia el Tribunal de Cuentas, ya que la caja no había enviado la cuenta general para su fenecimiento pasados los tres primeros meses del año, como lo establecían las reales órdenes. En ella se da cuenta de las funciones de cada empleado, de los ramos y cuentas de los que se hacen cargo y de la forma azarosa en la que además tienen que administrar los fondos:

Diez son los de dotación, el oficial mayor cuida de saber el estado de los expedientes que ruedan sobre la cobranza de los intereses reales para darles el curso que corresponda, lleva el libro de deudas, cuida de la correspondencia que es muy vasta y corre con los gastos de la oficina con otras más incidencias que tienen estos encargos; el segundo lleva los libros manual y común de cargo por cuya ocupación no le alcanza el tiempo y por eso casi todos los días, tiene que concluidas las horas de oficina quedarse en ella trabajando; lo mismo le sucede al que lleva el libro de data. Otro oficial está encargado de la mesa militar que no le deja lugar de otra cosa; dos están entretenidos solo en llevar los manuales de papel sellado, cuenta, razón y distribución de sus remesas y recibos. Dos, siempre están ocupados en llevar los libros de quintos y manifestaciones y en los que se copian los informes, consultas y cartas de correspondencia y en poner todo esto en limpio; dos que solo pueden estar destinados en llevar los manuales de bulas de cruzada e indultos, formar las planillas de su distribución, recibir las sobrantes 
y reconocer si son las que corresponden por las cuentas que dieren, que luego tenemos nosotros que revisarlas y fenecerlas; y otros dos que entienden en el pesadísimo trabajo de revisar y fenecer las cuentas de tributos y las que rinden los curas para el pago de las mesadas eclesiásticas; de modo que si no fuera por el auxilio de uno o dos entretenidos que siempre hemos procurado tener, estaríamos llenos de atraso, pues ya ve Vuestra Excelencia por esta ligera relación en que seguramente se nos han de haber pasado muchas cosas, como siendo solo diez los oficiales de dotación, se hallan ocupados doce, quedando sobre nosotros el peso de la mayor parte de los informes, de las consultas que se hacen a Vuestra Excelencia y de la actuación de los expedientes que le siguen servicio, y el material, y pesadísimo trabajo, de tener nosotros que contar personalmente todo dinero que entra y sale de la caja, punto sobre que omitimos discutir porque de ello se halla Vuestra Excelencia informado, por la representación que hicimos y con qué promovimos la creación de dos oficiales cajeros. (Caja Real de Santafé, 1805).

La elaboración y organización de las cuentas de la caja real, de algunas oficinas subalternas de ramos particulares, toma de correspondencia, administración de fondos y elaboración de expedientes eran el diario vivir de los oficiales de la caja, menesteres mucho más dispendiosos que la labor de solo revisar las cuentas y promover los reparos a la Junta Superior de Hacienda como lo hacía el Tribunal de Cuentas. Estos trabajos se vieron multiplicados por los nuevos modos de administración por vía directa y no por arriendo de algunos ramos, así como la creación de nuevos, y la delicada tarea de recibir y enviar situados (Caja Real de Santafé, 1805).

Desconocemos si la petición de dos cajeros fue atendida por el Virrey; sin embargo la representación deja claro que la trasformación del gobierno de la Real Hacienda implicó retos significativos para los organismos de control y administración. De esta forma se evidenció cómo las trasformaciones del fisco en Santaféllevaron al cambio paulatino de los organismos de control de la Real Hacienda, dando mayor peso a la administración real especializada en temas fiscales, en detrimento de instancias colegiadas como el cabildo de la ciudad y la Real Audiencia, gracias a la creación de la Superintendencia, la Dirección General de Rentas Estancadas, la Junta Superior de Real Hacienda y la implementación parcial del sistema de intendencias; un proceso que lejos de estar desprovisto de obstáculos, se encontró con la necesidad de reactualizar las plantas de algunas instituciones como el Tribunal Mayor de Cuentas y la caja real de Santafé, ante la ampliación de sus tareas.

\section{Conclusiones}

El reformismo borbónico en la Nueva Granada, y específicamente en la caja real de Santafé, estuvo marcado por una fuerte corriente centralizadora en la administración de los recursos del real erario, la estatización de rentas y parcialmente en la aplicación de las intendencias, tal y como aconteció en otras partes del imperio (Jáuregui, 2001). Varias son las señales de tal fenómeno, como el aumento de ramos de recaudo, la extensión territorial de las oficinas exactoras, la ampliación de la administración directa en detrimento del arrendamiento de rentas a nivel municipal y la aparición de organismos de control de los funcionarios encargados del fisco.

El aumento del número de los ramos como indicador de la aplicación de las reformas se dio previo a la llegada de la visita general de 1777, como lo sostienen Phelan (1982) o Pinto (2016b), a 1760 como expresa Meisel (2014), o por lo menos desde comienzos de la década del 50, lo que concuerda con la periodización propuesta por McFarlane (1997) sobre el inicio y desarrollo de las reformas. Ello también estuvo acompañado de un cambio de perfil de la caja, ya que sus principales fuentes de recaudo a comienzos de siglo estarían compuestas por los gravámenes a la minería y el tributo de indios, mientras que a finales de la centuria los estancos y las alcabalas llevarían la delantera.

La generación de nuevos ramos de cargo estuvo acompaña además de la necesaria apertura de nuevas oficinas recaudadoras con el objeto de tener un mayor control a nivel local. El análisis del mapa de estas oficinas entre 1705 y 1793 hizo evidente un proceso de densificación de oficinas pertenecientes al fisco en el territorio que comprende la cordillera oriental de la actual Colombia. Así las cosas, las reformas lograron consolidar toda una compleja red que abarcaba más de 150 puntos georreferenciados en donde existieron 
oficinas recaudadoras cuyos fondos terminaban en la caja matriz de Santafé, bien sea de forma directa o a través de las administraciones principales de rentas estancadas o alcabalas.

Tanto la fuerza del incremento de los ramos de cargo, la centralización y la densificación de la estructura de recaudo estuvieron acompañadas de la preocupación por mejorar su manejo.

Ante ello, el contador del Tribunal Mayor de Cuentas López y Campaña vislumbraba todo un reto en la trasformación de la administración y métodos de recaudo de diversas rentas poco después de instaurado el Virreinato, obligando al despliegue de medidas tendientes a un control más cercano por parte de las autoridades virreinales. Instituido este control, en algunos casos permitió limitar -aunque no eliminar totalmente- la influencia de corporaciones como la iglesia o los cabildos, en favor del nombramiento de administradores reales dependientes directamente de la caja de Santafé para sus pagos o de los premios otorgados para tal fin, supeditados al envío de sus cuentas a diversas instancias de control.

Por último, se evidenció la aparición de órganos de gobierno y vigilancia de la Real Hacienda, que descargó al Tribunal Mayor de Cuentas de la necesidad de revisar aquellas provenientes de las rentas estancadas -las más importantes del virreinato- a través de la creación de un propio tribunal para tal efecto bajo el nombre de Dirección General de Rentas Estancadas. Igualmente se limitó el pleno poder con el que contó la Real Audiencia en las decisiones de carácter contencioso en materias de hacienda, labor en la que empezó a tomar un mayor protagonismo el Virrey al ser nombrado Superintendente en 1751 y, a través de la creación de la Junta Superior de Real Hacienda en 1797, se permitió que las autoridades contables ya no tengan solo voto consultivo sino decisorio en los pleitos. Con base en ello, se pudo constatar la implementación parcial del sistema de intendencias en lo concerniente al plano contencioso y administrativo de la Real Hacienda en el territorio del Virreinato. Por último, se describió cómo este proceso no estuvo exento de sobresaltos ya que, por el contrario, estos abundaron debido a múltiples complicaciones nacidas en el seno de las diversas instancias encargadas del manejo y vigilancia del Real Erario.

Este trabajo permite abrir dos campos de discusión significativos. En primera instancia la historiografía reciente sobre la Nueva Granada ha explicado el incremento de los cargos de la Real Hacienda como producto del mejoramiento de las actividades económicas en el territorio (Meisel, 2011; Pinto, 2016b), dando por descontado o tratando marginalmente los cambios cualitativos que el gobierno de la hacienda tuvo durante el siglo XVIII. Ante ello, lejos de descontar el florecimiento de las actividades productivas, consideramos que el trabajo en términos de la comprensión del mejoramiento de los mecanismos de administración es una pieza complementaria que explica el incremento de los ingresos de la caja real de Santafé. Por último, si bien es cierto que la Nueva Granada no contó con una ordenanza de intendencias específica, sí tuvo un proyecto de implementación elaborado por Caballero y Góngora (Caballero, 1789), varios documentos de archivo tratan asuntos puntuales sobre la implementación de medidas contenidas en las ordenanzas de Buenos Aires y Nueva España. Por fin, aquí logramos extractar con toda claridad un documento que habla de su parcial ejecución en términos de Real Hacienda; razones que nos llevan a concluir que esta institución sí existió de manera parcial en el territorio neogranadino y que su estudio será pieza clave de futuras pesquisas.

Por último, también es evidente que el reformismo borbónico no fue un proceso concentrado en la década de los ochenta encabezado por José de Gálvez, pues este estuvo antecedido por medidas emprendidas durante la administración del Marqués de la Ensenada entre los años cuarenta y cincuenta, como así también por las directrices desarrolladas por el Contador Tomas Ortiz de Landázuri entre los años sesenta y setenta, de tal suerte que las modificaciones emprendidas en la caja real de Santafé mantenían una estricta relación con lo que acontecía y se diseñaba desde la metrópoli, conexión que debe también ser ampliada en futuros monográficos. 


\section{Referencias bibliográficAs}

Alves, A. y Sánchez, E. [falta año](2012). Introducción: guerra y fiscalidad en la Iberoamérica colonial. En A. Alvez y E. Sábnchez (Eds.), Guerra y fiscalidad en la Iberoamérica colonial (siglos XVII-XIX) (pp. 25-37). México: Universidade Federal de Juiz de Fora/Instituto de Investigaciones Dr. José María Luis Mora.

Astigarraga, J. (2000). Necker en España, 1780-1800. Revista de Economía Aplicada, 8 (23), 119-141.

Calderón, C. (1911). Elementos de hacienda pública. Bogotá: Imprenta de la Luz.

Contreras, C. (2014). Crecimiento económico en el Perú bajo los Borbones, 1700-1820. En J. Gelman, E. Llopis y C. Marichal (Coord.), Iberoamérica y España antes de las independencias, 1700-1820. Crecimiento, reformas y crisis. (pp. 75-110). México: Instituto de Investigaciones Dr. José María Luis Mora/El Colegio de México.

Deas. M. (2012). Prólogo. En J. Durán, Estado general de todo el Virreinato de la Nueva Granada en el presente año de 1794 (pp. 1-9). Bogotá: Banco de la República, 2013.

Dubet, A. (2016). El marqués de la Ensenada y la vía reservada en el gobierno de la Hacienda americana: un proyecto de equipo. Estudios de Historia Novohispana, 55, 99-116.

Dubet, A. (2018). Lerena y la reforma de la administración de la Hacienda española. En R. Torres (Dir.), Studium, Magisterium el Amicitia. Homenaje al Profesor Agustín González Enciso (pp. 405-412). Pamplona: Ediciones Funate.

Durán, J. (2012). Estado general de todo el Virreinato de la Nueva Granada en el presente año de 1794. Bogotá: Banco de la República.

Eissa-Barroso, F. (2015). La Nueva Granada en el sistema de Utrecht: condiciones locales, contexto internacional, y reforma institucional. En I. Escamilla, M. Souto y G. Pinzón (Coord.), Resonancias imperiales. América y el Tratado de Utrecht de 1713 (pp. 47-78). México: Instituto de Investigaciones Dr. José María Luis Mora e Instituto de Investigaciones Históricas de la Universidad Autónoma de México.

Gelman, J. y Moraes, I. (2014). Las reformas borbónicas y las economías rioplatenses: cambio y continuidad. En J. Gelman, E. Llopis y C. Marichal (Coord.), Iberoamérica y España antes de las independencias, 1700-1820. Crecimiento, reformas y crisis (pp. 21-74). México: Instituto de Investigaciones Dr. José María Luis Mora/El Colegio de México.

Giraldo, G (1954). Relaciones de mando de los virreyes de la Nueva Granada. Bogotá: Banco de la República.

González, M. (2005). Ensayos de historia colonial colombiana. Bogotá: El Áncora Editores.

Gutiérrez, F. (1792). Instrucción general para la recaudación del real ramo de alcabala y armada de Barlovento del Nuevo Reino de Granada. Santafé: Imprenta de D. Antonio Espinosa de los Monteros.

Ibarra, A. (1998, 2001). De la alcabala colonial a la contribución directa republicana. Cambio institucional y continuidad fiscal en una economía regional mexicana, Guadalajara 1778-1834. En L. Jáuregui y J. Serrano (Eds.), Finanzas y politica en el mundo Iberoamericano. Del antiguo régimen a las naciones independientes (pp. 317-350). México: Universidad Autónoma del estado de Morelos/Instituto de Investigaciones Dr. José María Mora/Universidad Autónoma de México.

Jáuregui, L. (1998, 2001). Del intendente al comisario: la herencia novohispana en la administración fiscal novohispana. En L. Jáuregui y J. Serrano (Eds.), Finanzas y política en el mundo Iberoamericano. Del antiguo régimen a las naciones independientes (pp. 223-254). México: Universidad Autónoma del estado de Morelos/ Instituto de Investigaciones Dr. José María Mora/Universidad Autónoma de México.

Jáuregui, L. y Marichal C. (2014). La economía mexicana desde la época borbónica hasta las guerras de independencia, 1760-1810. En J. Gelman, E. Llopis y C. Marichal (Coord.), Iberoamérica y España antes de las independencias, 1700-1820. Crecimiento, reformas y crisis (pp.111-162). México: Instituto de Investigaciones Dr. José María Luis Mora/El Colegio de México.

Klein, H. (1973). Structure and Profitability of Royal Finance in the Viceroyalty of the Rio de la Plata in 1790. The Hispanic American Historical Review, 53 (3), 440-469. 
Marino, D. [falta año]. (2001). El afán de recaudar y la dificultad en reformar. El tributo indígena en la Nueva España tardocolonial. En C. Marichal y D. Marino (Comp.), De colonia a nación. Impuestos y política en México, 1750-1860. México: El Colegio de México.

McFarlane, A. (1997). Colombia antes de la independencia. Economia, sociedady politica bajo el dominio borbón. Bogotá: Banco de la República / El Áncora Editores.

Meisel, A. (2011). Crecimiento, mestizaje y presión fiscal en el virreinato de la Nueva Granada, 1760-1800. Cuadernos de Historia Económica y Empresarial, 28, 1-96.

Meisel, A. (2014). Los ingresos fiscales y la economía del virreinato de Nueva Granada, 1761-1800. En J. Gelman, E. Llopis y C. Marichal (Coord.), Iberoamérica y España antes de las independencias, 1700-1820. Crecimiento, reformas y crisis (pp. 265-306). México: Instituto de Investigaciones Dr. José María Luis Mora/El Colegio de México.

Mora, G. (1988). Aguardiente y conflictos sociales en la Nueva Granada durante el siglo XVIII. Bogotá: Universidad Nacional de Colombia.

Muñoz, E. (2010). La estructura del ingreso y del gasto en la caja real de Santafé, 1803-1815. Anuario Colombiano de Historia Social y de la Cultura, 37(2), 45-85.

Navarro, L. (1995). Las reformas borbónicas en América el plan de intendencias y su aplicación. Sevilla: Universidad de Sevilla.

Ots Capdequí, J (1946). Nuevos aspectos del siglo XVIII español en América. Bogotá: Editorial Centro.

Phelan, J. (1980). El pueblo y el rey. Bogotá: Carlos Valencia Ediciones.

Pinto, J. (2015). Fiscalidad e independencia en Santafé y Bogotá, 1780-1830. América Latina En La Historia Económica, 22(3), 7-43.

Pinto, J. (2016a). El reformismo fiscal borbónico en la Nueva Granada, balance y perspectivas. Historia Caribe, 11(29), 53-82.

Pinto, J. (2016b). Reformismo borbón y fiscalidad en la Nueva Granada, 1750-1809. Recuperado de http://www.icanh.gov.co/nuestra_entidad/grupos_investigacion/grupo_historia_colonial_republicana/res ultados_proyectos_investigacion_6472/13694

Pinto, J. (2018). Entre colonia y república. Fiscalidad en Colombia, Ecuador y Venezuela, 1780-1845. Bogotá: Instituto Colombiano de Antropología e Historia.

Restrepo, M. (2009). Nueva Granada en tiempos del virrey Solís, 1753-1761. Bogotá: Universidad del Rosario y Universidad de Medellín.

Rodríguez, O. (1987). La caja real de Popayán, 1783-1800. Anuario Colombiano de Historia Social y de la Cultura, 15, 5-36.

Rojas, J. (2001). El Tribunal de Cuentas de Santafé. Bogotá: Ediciones Cardozo.

Sánchez, E. (1998). La hacienda reformada: la centralización de la renta de alcabalas en Nueva España (1754-1781). En L. Jáuregui y J. Serrano (Eds.), Finanzas y politica en el mundo Iberoamericano. Del antiguo régimen a las naciones independientes (pp. 143-179). México: Universidad Autónoma del estado de Morelos/Instituto de Investigaciones Dr. José María Mora/Universidad Autónoma de México.

Sánchez, E. (2013). Corte de caja. La Real Hacienda de Nueva España y el primer reformismo fiscal de los Borbones (1720-1755). Alcances y contradicciones. México: Instituto de Investigaciones Dr. José María Luis Mora.

Sánchez, E. (2016). La imperiosa necesidad. Crisisy colapso del erario de Nueva España, 1808-1821. México: Instituto de Investigaciones Dr. José María Luis Mora, El Colegio de Michoacán y Consejo Nacional de Ciencia y Tecnología.

Sánchez, E. (2017). Los libros de la razón general de Real Hacienda como instrumentos de gobierno del Erario de Nueva España (1786-1818): una obra inconclusa. Estudios de Historia Novohispana, 57, 79-96.

Sánchez, R. (2014). Las salinas del Virreinato y el Estanco de la sal. Una visión de conjunto a finales del siglo XVIII. Recuperado de http://www.icanh.gov.co/nuestra_entidad/grupos_investigacion/historia_colonial/resultados _proyectos_investigacion_6472/12135 
Torres, J. (2016). Administración, fiscalidad y monopolio de la renta de tabaco en el virreinato de Nueva Granada (1778-1810). Recuperado de http://www.icanh.gov.co/nuestra_entidad/grupos_investigacion/grupo_historia _colonial_republicana/resultados_proyectos_investigacion_6472/13696

Torres, R. (2018). Tejiendo una hacienda imperial. "Unir los manejos de la Real Hacienda de España y América" en el reinado de Carlos III. En M. Bertrand y Z. Moutoukias (Eds.), Cambio institucional y fiscalidad. Mundo hispánico, 1760-1850 (pp. 43-64). Madrid: Casa Velásquez.

Varela, M. (2018). Atlas: Proceso de Deconstrucción y Reconstrucción de los Paises Bolivarianos, 1400-2017. Barinas: Universidad Nacional Experimentales de los Llanos Occidentales Ezequiel Zamora.

\section{Fuentes de Archivo}

Administración de Alcabalas De Santafé (1802). Criminales contra Juan Diaz de Herrera Administrador de alcabalas de esta capital por alcance que le resultó del tiempo de su manejo. Archivo General de la Nación. Colombia. Sección: Colonia. Fondo: Alcabalas. Tomo: 1.

Amar, A. (1806). Decreto del Virrey Antonio Amar del 25 de noviembre de 1806 inhibiendo a la Real Audiencia en materias de Real Hacienda. Archivo General de la Nación. Colombia. Sección: Colonia. Fondo: Virreyes. Tomo: 14.

Caballero, A. (1789). Recomendaciones del Virrey Antonio Caballero y Góngora para la instauración de las Intendencias en el Virreinato de la Nueva Granada. Archivo General de la Nación. Colombia. Sección: Colonia. Fondo: Virreyes. Tomo: 17.

Caja Real de Santafé (1778). Distinción de las rentas reales y distinción de ramos desde el primitivo establecimiento de estas cajas de la ciudad de Santafé. Archivo General de la Nación. Colombia. Sección: Archivo Anexo I. Fondo: Real Hacienda. Tomo: 37.

Caja Real de Santafé (1784). Razón de los valores de los ramos de Real Hacienda de esta caja, sus cargas y pensiones para el quinquenio corrido entre 1732 y 1737. Archivo General de Indias. Santafé, 784.

Caja Real de Santafé (1792). Manifiesto por relaciones y estados de los ramos de la Real Hacienda que se administran en esta tesoreria de Santafé de Bogotá, formado en cumplimiento de la real orden de 21 de junio de 1790 y con arreglo al papel de advertencias prescriptas al intento por el excelentísimo señor virrey en 16 de octubre del mismo año. Archivo General de la Nación. Colombia. Sección: Archivo Anexo I. Fondo: Real Hacienda. Tomo: 6.

Caja Real de Santafé (1805). Representación de los oficiales de la caja real de Santaféa al Virrey Antonio José Amary Borbón. Archivo General de la Nación. Colombia. Sección: Colonia. Fondo: Miscelánea. Tomo: 15.

Gutiérrez, F. (1779). Instrucción para el gobierno de la dirección general de la renta de aguardiente de caña en el Nuevo Reino de Granada, provincia de Tierra Firme y gobernación de Popayán. Biblioteca Nacional de Colombia. Fondo: Comuneros. Tomo 1.

Gutiérrez, F. (1780). Nuevo plan e instrucción para el gobierno de las cuatro rentas unidas de tabaco, aguardiente, naipes y pólvora mandada establecer en esta capital. Biblioteca Nacional de Colombia. Fondo: Comuneros. Tomo 5.

López, P. (1790). Real Orden del 21 de junio de 1790. Archivo General de la Nación. Colombia. Sección: Colonia. Fondo: Real Hacienda cartas. Caja: 33 Carpeta: 1

López y Campaña, A. (1747). Los herederos del Contador Felipe Antonio López en comprobación de sus méritos y servicios a su majestad. Archivo General de la Nación. Colombia. Sección: Colonia. Fondo: Real Hacienda. Tomo: 68.

Recopilación de Leyes de los Reinos de Indias (1681). Libro VIII. Título III. Ley VIII. Madrid.

Somodevilla, Z. (1751). Real Orden de 30 de junio de 1751. Archivo General de la Nación. Colombia. Sección: República. Fondo: Restrepo. Serie: Revoluciones de la Nueva Granada, Quito y Venezuela. Vol. 19. Cédulas y Reales Órdenes.

Terreros, F (1705). Libro perteneciente al Francisco Terreros. Archivo General de la Nación. Colombia. Sección: Archivo Anexo I. Fondo Real Hacienda. Tomo: 4.

Tribunal Mayor de Cuentas De Santafé (1737). Estado general de valores de la caja real de Santafé del quinquenio 1732-1737. Archivo General de Indias. Contaduría, 1377. 
Tribunal Mayor de Cuentas de Santafé (1788). Representación del Tribunal Mayor de Cuentas de Santafé al Virrey Caballero y Góngora. Archivo General de la Nación. Colombia. Sección: Colonia. Fondo: Real Hacienda. Tomo: 63.

\section{Notas}

1. El presente artículo es resultado del proyecto de investigación "Fiscalidad en la caja real de Santafé, 1750-1808” código 180117, financiado por la Oficina de Investigaciones y Desarrollo Científico de la Universidad del Tolima.

2. Ver: Sánchez, 2013, pp. 14-26.

3. Este tipo de labores no era ajena al conjunto de la monarquía y al desempeño del Ministro Lerena, ya que parte fundamental de las reformas emprendidas por este se basó en la recopilación de información sobre el funcionamiento administrativo de la Real Hacienda en gran parte de América (Dubet, 2018). Entre estas empresas se encuentra la recopilación de las leyes de hacienda de España (Astigarraga, 2000), así como la realización de razones generales de la Real Hacienda, donde se daba un panorama histórico del comportamiento de este asunto en las Indias (Sánchez, 2017).

4. Es preciso recordar que la gruesa decimal era distribuida en partes, una de las cuales quedaba a disposición del cabildo (cuarta capitular) y otra del episcopado (cuarta episcopal). Las restantes dos cuartas, es decir, el 50 \% de la masa decimal, se dividían en nueve partes, de las cuales dos eran para la Real Hacienda (reales novenos), una y media para la fábrica de iglesias, una y media para la fábrica de hospitales y cuatro para los curas y los sacristanes. A partir de 1804 una novena parte de la masa decimal antes de la división en cuartas pertenecía a la Real Hacienda para la consolidación de vales reales (Pinto, 2018). 